\title{
Los intereses económicos de Eistados Unidos y su política hacia América Latina
}

Los intereses económicos han tenido la primera importancia en la política de EE. UU. hacia América Latina. Son numerosos los casos de conflicto entre gobiernos latinoamericanos y empresas norteamericanas en los cuales el Gobierno de EE. UU. intervino a favor de las empresas. También es obvio que las políticas de EE. UU. han intentado crear en cada país condiciones favorables a las inversiones norteamericanas para explotar recursos y extraer utilidades de América Latina. Con frecuencia, la política económica externa de EE.UU. se ha puesto al servicio de objetivos políticos. Ha servido para obstruir procesos de transformación económica y reformas aceleradas o para respaldar a gobiernos cuya permanencia en el poder resulta de interés para la Administración norteamericana.

En el período reciente, las relaciones económicas entre América. Latina y EE. uU. se han hecho más complejas y han comenzado a predominar consideraciones globales, en reemplazo de las hemisféricas. La "relación especial" se ha desvanecido, y las formas más simples de influencia económica directa del Gobierno de EE.UU, han. ido dejando paso a una relación más indirecta y global. ¿Guál es la nueva lógica de los intereses económicos de EE. UU. en América Latina? ¿Qué cambios han ocurrido en la década de los setenta? ¿Cómo influyen esos cambios en la política externa y de seguridad de ese país?

Para intentar una respuesta distinguiremos tres objetivos económicos de EE. UU. que inciden en su política para América Latina: a) la defensa de los intereses de las empresas privadas en el exterior; b) la asistencia para el desarrolla económico de la región y c) el resguardo del sistema económico global de libre mercado y de empresa privada.

La importancia de estos tres objetivos ha cambiado con el tiempo. El primero ha perdido significación, el segundo prácticamente ha sido descartado $y$ el tercero ha ganado preponderancia. Este cambio ha incidido sobre las políticas de $\mathrm{EE}$. UU. Y tiene nuevas consecuencias sobre América Latina.

\section{LA DEFENSA DE LAS INVERSIONES NORTEAMERIGANAS} EN AMÉriga LATINa.

La modalidad de defensa de las inversiones norteamericanas ha va- 
riado en la última década. Las primeras fases, hasta Ios años sesenta, se caracterizaron por una política activa y por una rápida expansión. Desde las primeras décadas de este siglo el interés consistió en acceder a los recursos minerales, materias primas agrícolas y algunos servicios públicos. Muchas de las inversiones eran también de cartera. A partir de los años sesenta adquirió gran relevancia la corporación transnacional, a través de sus subsidiarias. En esa década, la presencia norteamericana alcanzó su apogeo y era indisputada en América Latina. Esas empresas fueron haciendo sentir cada vez más su influencia en el estilo de desarrollo y en la política interna de los países latinoamericanos.

Desde los años cincuenta, numerosos países latinoamericanos comenzaron a reaccionar nacionalizando aquellas empresas que operaban en recursos naturales. En los sesenta y setenta establecieron los primeros cuerpos legales para controlar la operación de las transnacionales. Además, comenzaron a negociar nuevas condiciones para conseguir un mayor aporte de las subsidiarias extranjeras a los objetivos nacionales (exportaciones, tecnología, procesamiento local, remesas...).

Desde mediados de los sesenta, la política de EE. UU. fue evolucionando desde una postura activa y expansiva de sus inversiones hacia una más defensiva de los intereses ya adquiridos. Primero, se completaron las legislaciones para adoptar represalias, tales como las Enmiendas Hickenlooper y González. Se precisaron, por parte del Presidente de EE. UU. las condiciones de una compensación justa y oportuna, en caso de nacionalización, para mantener relaciones normales. Segundo, EE. uU. comenzó a establecer normas generales para asegurar un desenvolvimiento menos conflictivo de sus corporaciones. Comenzó a impulsar los Bilateral Investment Treaties, las. propuestas del GATT para legislar sobre performance requirements; las sugerencias para establecer órganos internacionales para la resolución de disputas, etc. También el Gobierno de EE. UU. se ha opuesto al Código de Conducta propuesto por UNGTAD con el respaldo de los países en desarrollo. Tercero, el Gobierno de EE. UU se volvió más cauteloso en sus disputas con los gobiernos latinoamericanos. También las corporaciones se tornaron más reticentes a acoger imposiciones del Gobiemo de EE. UU. que pudieran contrariar a los gobiernos de los países donde operan sus subsidiarias.

Esta evolución, motivada tanto por cambios en la economía mundial, como en la economía norteamericana y en las latinoamericanas, ha tenido importantes consecuencias. La más relevante que interesa destacar aquí es que la defensa por parte del Gobierno de EE. UU. de los intereses de corporaciones transnacionales ha cambiado de naturaleza. Ello no se verifica, como antes, mediante un respaldo oficial a cada corporación frente a los gobiernos latinoamericanos, sino que se busca ahora la implantación de normas globales 
que sean acordadas por Ios estados, multilateralmente. Se trata de evitar conflictos entre estados que suelen tener muchas más ramificaciones.

\section{LA PROMOCIÓN DEL DESARROLLO ECONÓMICO DE AMÉRICA LATINA}

El segundo objetivo económico de la política externa de EE.UU. hacia América Latina ha sido la promoción del desarrollo.

La experiencia del Plan Marshall en Ios cuarenta y cincuenta conjuntamente con las ideas que tomaron cuerpo en América Latina en favor del desarrollo y de las reformas económicas y sociales sirvieron de base para la Alianza para el Progreso. El programa de esa Alianza constituyó, sin duda, la culminación de los esfuerzos de cooperación hemisférica en este siglo.

Hasta fines de los sesenta, algunos sectores del Gobierno norteamericano sostuvieron la conveniencia de promover el desarrollo de América Latina como un objetivo de la política externa de EE.uU. Después de esa fecha, las condiciones comenzaron a cambiar en EE.UU. $y$ en América Latina. En ex.uU. la guerra de Vietnam y los problemas económicos internos limitaron cada vez más los recursos oficiales destinados a asistencia. También comenzó a argumentarse que la ayuda económica tenía poco efecto, pues la solución de los problemas dependía básicamente de las acciones que tomaran internamente los gobiemos latinoamericanos. Por último, quienes defendían la idea de que el desarrollo era un requisito para la estabilidad política se vieron confrontados por quienes sostenían que la inestabilidad inmediata estaba vinculada a la capacidad de control político y no a la superación de problemas estructurales que siempre hablan existido y cuya solución requiere de plazos muy largos.

En América Latina las dificultades políticas para emprender re. formas y la magnitud creciente de los recursos financieros necesarios para impulsar el desarrollo también redujeron la efectividad que podían tener los fondos que EE.UU. estaba en condiciones de prestar.

La tesis de que el desarrollo económico y social de América Latina era parte de la ecuación de seguridad de EE.UU. comenzó a debilitarse. Si bien ha continuado sosteniéndose en palabras, en la práctica no ha tenido implementación. La asistencia financiera oficial de EE.UU. comenzó a disminuir rápidamente y en su reemplazo cobró cuerpo la tesis trade not aid, señalándose que una mejor forma de aportar al desarrollo de América Latina era mediante preferencias comerciales o inversiones directas y un crecimiento sostenido de la propia economía norteamericana.

EI Sistema Generalizado de Preferencias, establecido en 1975 tuvo, sin embargo, escasa amplitud y poca flexibilidad. Las preferen- 
cias comerciales también comenzaron a disminuir hacia fines de los setenta. La política de fomento al desarrollo económico en América Latina también bajó considerablemente. La escasa magnitud del financiamiento bilateral permanece ligada fundamentalmente a la seguridad. Se concentra en países pequeños, sea para respaldar a los "amigos", o para debilitar a los "hostiles".

En sintesis, ha tendido a desaparecer de la política económica externa de EE.UU toda acción destinada a fomentar directamente, mediante apoyos de carácter hemisférico, el desarrollo latinoaniericano.

\section{EL FUNGIONAMIENTO ESTABLE DEL SISTEMA GLOBAL}

El tercer objetivo económico de la política externa de EE.UU. es la expansión y defensa de un sistema económico internacional sustentado en el principio de libre mercado y de empresa privada.

Este objetivo tiene distintos componentes. Por una parte, un sistema abierto es más conveniente para la expansión de los intereses económicos de EE.UU. a nivel mundial. En el campo financiero, comercial, tecnológico y de inversiones, EE.UU. mantiene mejor su liderazgo. Además, este sistema permite a los principales países desarrollados aliados de eE.uv. un crecimiento más acelerado y una mayor presencia en la economía mundial.

A medida que se aceleró la globalización de los fenómenos económicos, para EE.UU. fue adquiriendo más importancia la necesidad de regular y preservar un funcionamiento fluido de la economía mundial. En la década de los setenta, la economía norteamericana elevó su grado de apertura internacional. En el terreno comercial;: prácticamente se duplicó el coeficiente de comercio exterior sobre el producto. En el terreno financiero, los bancos norteamericanos se extendieron mundialmente y comprometieron considerables recursos en casi todos los países del mundo. Esa apertura, junto con el fortalecimiento económico de otras regiones del planeta, hicieron que la economía norteamericana resintiera más los factores económicos externos. El crecimiento de la economía y del comerciomundial, la lucha contra la inflación y el desempleo se transformaron en tareas que no podían ser enfrentadas sólo por EE.UU. y que. requerian de la acción concertada de los grandes países.

Esta nueva realidad ha tenido una importante consecuencia: ha. crecido la relevancia estratégica para EE.UU. de la mantención de un funcionamiento sin crisis de la economía mundial. Este ha pasado a ser el objetivo fundamental de la política externa de EE.UU.

La preservación de un sistema global abierto, con predominio del sector privado (esencialmente corporaciones y bancos transnacionales) tiene diversas implicaciones. Desde el punto de vista norteamericano, no basta con que los países participen en la economía 
mundial respetando las normas establecidas por las economías desarrolladas y sus empresas y bancos. Cada pafs debe tener un ordenamiento económico interno donde predomine o tenga importante gravitación el sector privado. Ideológicamente, EE.UU. promueve la. empresa privada y se opone a la expansión del estado. En el terreno político, las administraciones norteamericanas mantienen su oposición a las transformaciones económicas nacionales que impliquen un cambio en las formas de propiedad o que causen un perjuicio al capital privado. La premisa central es que un sistema global de mercado libre debe reposar en economías nacionales de mercado libre, y esto también vale para el Tercer Mundo.

\section{NUEVAS PRIORIDADES PARA EE.UU.}

Estos tres objetivos económicos de EE.UU. en América Latina están interrelacionados. En efecto, las polfticas de promoción del desarrollo, especialmente en los países más pequeños, favorecen la instalación y expansión de los intereses norteamericanos. Esto ocurre por varias vías. Primero, la asistencia financiera, y los créditos oficiales son más generosos para los gobiernos "amigos" y están ligados a ciertos objetivos de seguridad. Segundo, en la medida que la inversión directa es proyectada como una forma de ayuda al desarrollo, el gobierno de EE.UU. suele requerir de los países la creación de un "clima fayorable", lo cual implica otorgar incentivos a las corporaciones norteamericanas. Tercero, los créditos oficiales, preferencias comerciales y otros arreglos generan una mayor demanda de productos norteamericanos, agricolas e industriales.

El objetivo de EE.UU. de expandir y mantener el sistema global también facilita la defensa de las inversiones extranjeras y supuestamente contribuye al desarrollo económico de la región. La existencia de normas comerciales globales a través del GATr, de criterios financieros y de política económica a través del FMI, son coadyuvantes a la expansión de los intereses de EE.UU. Los países latinoamericanos se hallan insertados en el sistema global, deben acatar Ias normas internacionales y deben adoptar políticas económicas no antagónicas con las propiciadas por los principales actores internacionales, sean ellos el gobierno de EE.UU., las organizaciones internacionales, la comunidad bancaria o las corporaciones transnacionales. De acuerdo a la lógica de la polftica económica internacional de EE.UU., se presume que un sistema así regulado es más favorable para los países de América Latina, pues alienta el libre comercio, las exportaciones y el flujo de inversión extranjera.

La prioridad otorgada por EE.Uu. a estos tres objetivos - defensa de intereses especificos, promoción del desarrollo y defensa del sistema global- ha cambiado en los últimos años. Este cambio ha sido consecuencia de. las transformaciones globales. Ia economía 
mundial se ha hecho más compleja e interdependiente. El número de actores ha aumentado y la fuerza relativa de ellos es menos asimétrica que antes. EE.UU. ha perdido parte de su poder para imponer sus criterios. Los países de Europa y Japón han adquirido más peso en la economía mundial. Las transnacionales europeas y japonesas han tomado el liderazgo en varias actividades manufactureras y de servicios. Numerosos países en desarrollo han alcanzado una dimensión mayor, tienen más autonomáa de decisión y participan más activamente en la economía internacional.

Al mismo tiempo, los problemas económicos domésticos de EE.UU. han ido restringiendo Ia disponibilidad de recursos financieros oficiales para influir directamente en las decisiones de otros estados. Tales recursos han disminuido considerablemente como proporción de los fondos externos utilizados por los países latinoamericanos $y$ también como proporción del PGB de $\mathrm{EE}, \mathrm{UU}$. A su vez, las preferencias comerciales se han ido restringiendo, a medida que EE.UU ha adoptado una posición comercial más defensiva.

En este nuevo contexto, se lian verificado cambios importantes en las prioridades de la política económica de EE.UU. que afectan a América Latina. En primer lugar, ha declinado la importancia asignada al desarrollo económico de América Latina. Este objetivo ya no es prioritario. Se señala ahora que América Latina pertenece a la "clase media", que los problemas económicos son de responsabilidad de cada país y que los fenómenos globales se manejan a través de órganos multilaterales sobre los cuales EE.UU. no ejerce control. En segundo lugar, ha disminuido la capacidad de defensa de intereses específicos. Cada país posee más fuerza relativa respecto a cada empresa norteamericana o cada banco extranjero. Las relaciones entre el Gobierno de EE.UU. y cada gobierno de América Latina son más complejas y abarcan una mayor variedad de problemas, lo cual obliga a ponderar cuidadosamente un conflicto en función de los otros intereses en juego. Además, sobre la política externa de EE.UU. hay una incidencia creciente de los problemas económicos domésticos. Grupos de interés que antes no se ocupaban de temas económicos internacionales, ahora sí lo hacen y ello cambia el grado de autonomfa de que gozaba el Gobierno norteamericano para aplicar su política económica hacia América Latina.

Ha crecido en cambio la prioridad asignada a la mantención de un sistema global abierto. La política económica internacional norteamericana se ha concentrado en la coordinación de polfticas ecomicas con los otros países desarrollados para mantener una economía global en expansión, sin grandes distorsiones inflacionarias y de desocupación, ha priorizado la protección de los bancos internacionales, para evitar quiebras que podrían acarrear un desplome del sistema financiero, ha buscado evitar el proteccionismo comercial y ha promovido el fortalecimiento de los órganos multilaterales. 
El objetivo principal para EE.UU. sigue siendo el mismo: que Occidente mantenga su primacía económica y que EE.UU. conserve su hegemonía en el mundo desarrollado. Pero el cambio en la situación global ha obligado a modificar los instrumentos para lograr ese propósito.

\section{PODER ECONÓMTCO Y POLÍTIGA EXTERNA DE EE.UU. HACTa AMÉRICA LaATINA}

Los objetivos estratégicos globales de EE.UU. tienen una proyección económica que se traduce en las metas siguientes:

a) Una mayor fortaleza económica de EE.UU. y sus aliados frente a sus adversarios:

b) Una posición dominante de EE.uv. entre sus aliados;

c) Una posición económica hegemónica sobre los países del Tercer Mundo, a fin de mantener cierto control sobre su evolución. Se trata de evitar que se produzcan transformaciones económicas internas en esos países que sean antagónicas con el principio del libre mercado y que pueden generar una dinámica politica que favorezca a los adversarios de eE.UU.;

d) Una superioridad ideológica, fundada en el éxito nacional e internacional del sistema económico gobernado por los países desarrollados de Occidente.

La forma de alcanzar esos propósitos depende del cuadro económico general y de la fuerza relativa de EE.UU. La nueva situación ha llevado a EE.uv. a una posición más defensiva que antes. Con el fin de conservar su influencia, la política económica de EE.UU. hacia América Latina presenta dos nuevas características:

1) EE.uU. ha dado prioridad a la contención de las crisis económicas que afecten el funcionamiento global del sistema. EE.UU. se moviliza con rapidez, por ejemplo, para impedir la generalización de una crisis financiera, como la resultante de la postergación del pago de la deuda de los países de América Latina.

2) EE.UU. ha dado prioridad a una polftica que frene las transformaciones sociales más profundas o la implementación de esquemas económicos no capitalistas en el Tercer Mundo. Esto se expresa de distintas maneras: a) acciones destinadas a proporcionar asistencia financiera a los gobiernos de países que se consideran amenazados por la posibilidad de un giro en favor de transformaciones estructurales; b) una mayor subordinación de la asistencia económica a la asistencia militar; c) alianzas con sectores políticos internos que comparten intereses económicos con EE.UU. y d) la promoción de politicas económicas sustentadas en los principios del libre mercado, del tipo de las exigidas por el FMr. 


\section{Gonseguencias para América latina}

Este cambio de énfasis en las políticas económicas externas de EE.UU. tiene numerosas consecuencias para América Latina. Entre ellas conviene destacar:

a) EI desarrollo económico de la región, como objetivo directo de la política de EE.Uu., ha perdido prioridad. Por razones económicas y políticas se postula que el desarrollo incide débilmente en la mantención del orden interno en el corto y mediano plazo. EE.UU. no pretende aportar ni financiamiento ni preferencias comerciales. El caso del Caribbean Basin Initiative es una excepción y debe entenderse como un complemento de un plan militar.

b) EE.UU. ha perdido capacidad para proteger los intereses económicos específicos de corporaciones determinadas cuando entran en conflicto con gobiernos latinoamericanos. Propicia, a cambio, acuerdos mültilaterales para establecer normas para todos y acuerdos bilaterales de gobierno a gobierno (por ejemplo, bilateral intestment treaties).

c) El Gobierno de EE.uU. prefiere asignar su escasa asistencia financiera en forma bilateral y en función de los objetivos de seguridad. Estos fondos se concentran preferentemente en los países más pequeños.

d) El Gobierno de EE.uU. ha ido adoptando una posición mảs defensiva debido a la mayor competitividad de las exportaciones latinoamericanas y a las reacciones domésticas de las industrias afectadas. Ello implica reducir sus preferencias comerciales y su asistencia concesional a América Latina.

e) La política económica externa de EE.Uu. ha enfatizado la solución de problemas globales en forma multilateral, alejándose de los enfoques regionales. América Latina es tratada como una parte más del Tercer Mundo. EE.UU. ya no persigue una "relación económica especial" con América Latina y esta área es vista sólo como un componente secundario del sistema económico internacional.

Todos los señalamientos anteriores están vigentes en condiciones rutinarias. En circunstancias excepcionales, cuando sectores del Gobierno norteamericano perciben una amenaza para la seguridad, varía la política económica de EE.uU. hacia América Latina. El Gobierno norteamericano opera en forma rápida y más coordinada cuando percibe situaciones de crisis para sus intereses en América Latina. Se pueden distinguir dos tipos de situaciones de crisis cuyo origen es económico. Primero, aquellas situaciones locales que repercuten sobre el sistema económico global, y segundo, aquellas que pueden amenazar la estabilidad política interna de un país, en forma que EE.UU. considera amenazante para sus intereses estratégicos. 
Las primeras son improbables. La única y más importante hasta ahora ha sido la crisis financiera derivada de la deuda externa de América Latina, a comienzos de los años ochenta. Nunca antes América Latina pudo generar un problema económico que afectara directamente intereses significativos de EE.UU. En el caso de la deuda, América Latina cobró una fuerza que puso en cuestión la estabilidad de los grandes bancos de EE.vU. y de otros países desarrollados. La reacción norteamericana en favor de facilitar los recursos financieros y hacer más expeditas las renegociaciones de la deuda, no debe interpretarse como resultado de un interés particular por aliviar las tensiones de América Latina, sino para proteger la salud de sus bancos.

Las segundas han sido más frecuentes. Se trata de aquellas crisis de estabilidad política generadas por desajustes económicos graves o cambios político-económicos que pueden derivar en transformaciones estructurales y en nuevas relaciones de poder. En tales circunstancias, también ocurren ajustes en la política económica de EE.UU. Estos ajustes se expresan de distintas maneras. En unos casos, mediante presiones para defender corporaciones norteamericanas, en otros mediante la negación de créditos oficiales o votos contrarios en los organismos internacionales y diversas formas de obstrucción del comercio. También, se ha expresado en un apoyo económico privilegiado a aquellos gobiernos que pretenden contener los cambios acelerados o aquellas naciones cuya estabilidad y régimen político interesa preservar a EE.UU. para evitar desajustes graves, con implicaciones políticas y de seguridad, como ocurre con paises de mayor tamaño, especialmente México.

Sin embargo, a medida que las relaciones económicas tienden a ser más globales e interdependientes y a medida que el Gobierno de EE.UU. se ve obligado a coordinar sus decisiones con otros países desarrollados, su poder de influencia directa sobre los gobiernos latinoamericanos tiende a disminuir. Esto ha estado ocurriendo en los últimos años.

A medida que el poder económico ya no es ilimitado para lograr los objetivos propuestos y que esos objetivos no son ajustados a una nueva relación de fuerzas económicas, se tiende a producir una tensión que debe ser resuelta. Tal resolución puede provenir de dos distintos enfoques. El primero, es compensar unos instrumentos de poder -los económicos- por otros. Para compensar la pérdida de poder económico, EE.UU. ha recurrido más a los componentes militar, político e ideológico en su política hacia América Latina. El segundo, es reacomodar los intereses en conflicto y aceptar que América Latina asuma mayores responsabilidades internas e internacionales. Este no ha sido el camino seguido por los gobiernos de EE.UU., menos aún por la Administración Reagan. Sin embargo, a 
mediano plazo debería producirse una adaptación de las polfticas externas de EE.UU. a la nueva relación de fuerzas económicas con América Latina. La velocidad y naturaleza de adaptación dependerá, en buena medida, de la capacidad de coordinación latinoamericana para elevar su poder económico relativo frente a EE.UU. 